\title{
Determinants of different birth intervals of ever married women: Evidence from Bangladesh
}

\author{
Benojir Ahammed*, Md. Rasel Kabir, Md. Menhazul Abedin, Mohammad Ali, Md. Akhtarul Islam \\ Statistics Discipline, Khulna University, Khulna, 9208, Bangladesh
}

\section{A R T I C L E I N F O}

\section{Keywords:}

Birth interval

Censored observation

Ever married women

Survival analysis

\begin{abstract}
A B S T R A C T
Introduction: The analysis of factors affecting birth interval helps to reveal the mechanism and dynamics of fertility behavior which changes the population structure of a country.

This study aims to examine the association among different socioeconomic and demographic factors with birth intervals and to identify the statistically significant factors of birth intervals.

Material and methods: This study has been used latest Bangladesh Demographic and Health Survey 2014 data based on two stage stratified sample of households. Different birth intervals have been analyzed using various statistical techniques such as Kaplan Meier estimator, log rank test, Cox proportional hazard model and Frailty model.

Results: Among the ever married women, 92.40\%, 76.80\% and 61.60\% have experienced live birth for first, second and third times, and the estimated median duration of birth intervals are 26, 46, and 58 months, respectively. Using the log rank test, this study found that region, place of residence, mothers education, partners education, contraceptive use, and mothers age are significantly associated with birth intervals. This study also considered mothers age and working status at first birth interval; mothers education, age, working status and survival status of previous child at second birth interval; mothers education, sex of household head, working status, mass media exposure, age, contraceptive use, religion, and survival status of previous child at third birth interval are protective factors in next births.

Conclusions: Overall, mothers age, working status and mass media exposure are protective factors in birth intervals. To fulfill the target, government should pay attention to significant protective factors.
\end{abstract}

\section{Introduction}

Nowadays over population is the most alarming problem. Excess population growth is a big and challenging problem in Bangladesh and this growth varies significantly due to social, regional and educational factors. One of the important determinants of population growth is fertility, that plays the most important role in changing the size and structure of population ${ }^{1}$ and it is identified as the main cause of increasing the growth of population. ${ }^{2,3}$ Fertility analysis is essential for policy makers to get guidance for population control and evaluation of family planning programs. ${ }^{4}$ Fertility depends on the couple's decisions, effective reproductive period, duration of the length of birth intervals, socioeconomic, health related, and emotional factors. The intrinsic growth rate as well as the mean generational length of any population may get affected by the birth interval. ${ }^{5}$ This is the main evidence that the birth interval is the key factor in population growth. Furthermore, information on birth interval provides an insight into birth spacing patterns, which affect fertility as well as maternal, infant, and childhood mortality.

A birth interval is defined as the time between two successive live births. ${ }^{6}$ The duration of birth intervals has received attention in demography and public health research because of its influential implication on fertility and hazardous impact on both maternal and child health. Several maternal and child health problems may occur due to birth interval of less than 17 months or more than 5 years. Different studies have been shown that short birth interval is associated with high risk of both mother and baby death, particularly when the birth interval is less than 18 months. $^{7}$ It is evidence that there is no universally accepted optimal birth interval. ${ }^{8,9}$ Zhu et al. suggests that the first birth interval should be 18-23 months to avoid the adverse prenatal outcomes. ${ }^{8}$ According to Clayton, the optimal interval to ensure survival through childhood is 3 years and 9 months. ${ }^{10}$ Martin deduced that a

\footnotetext{
* Corresponding author.

E-mail addresses: benojirstat@gmail.com (B. Ahammed), raselsh023@yahoo.com (Md. R. Kabir), menhaz70@gmail.com (Md. M. Abedin), ali.ru.stat@gmail.com (M. Ali), akhtarulstat@gmail.com (Md. A. Islam).
} 
Table 1

The category of demographic and socio-economic characteristics with identification code.

\begin{tabular}{ll}
\hline Demographic and socio-economic characteristics & Categories (code) \\
\hline Region/Division & Barisal (1), Chittagong (2), Dhaka (3), Khulna (4), Rajshahi (5), Rangpur (6), Sylhet (7) \\
Place of residence & Urban (1), Rural (2) \\
Mothers education & No education (0), Primary (1), Secondary (2), Higher education (3) \\
Partners education & No education (0), Primary (1), Secondary (2), Higher education (3) \\
Mothers age & $\leq 20$ years (1), 21-30 years (2), $\geq 31$ years (3) \\
Mothers working status & No (0), Yes (1) \\
Contraceptive use status & No (0), Yes (1) \\
Sex of household head & Male (1), Female (2) \\
Religion & Muslim (0), Non-Muslim (1) \\
Wealth index & Poor (0), Middle (1), Rich (2) \\
Mass media exposure & No (0), Yes (1) \\
Sex of previous child & Boy (1), Girl (2) \\
Survival status of previous child & Dead (0), Alive(1) \\
Previous birth interval & $<24$ months (1), 24-48 months (2), > 48 months (3) \\
\hline
\end{tabular}

minimum of 2 years spacing is necessary between births for the best physical and mental development, but three years spacing would be even better. ${ }^{11}$

Generally, birth intervals are higher in Bangladesh and increasing day by day. Lengthy breastfeeding and a long period of postpartum amenorrhea are the main factors of high percentage of births occurring after an interval of 24 months or more. Bangladesh has been achieved a remarkable demographic transition over the last two decades. The aim of the health sector programs those were conducted in Bangladesh is to reach a fertility level of two births per woman within $2016 .{ }^{12}$

Total fertility rate significantly declined from 1970 to 2014 . $^{12}$ However, birth interval is affected by several factors. Some women are experienced very short birth interval whereas some too long and the rest just normal. This study intends to identify the factors affecting first, second and third birth intervals separately and assess their impacts on birth intervals.

\section{Methods}

\subsection{Data sources}

The current study uses the nationally representative secondary data extracted from Bangladesh Demographic and Health Survey (BDHS) 2014. The survey is intended to serve as a source of population and health data for policy makers and the research communities in Bangladesh. The survey was implemented by a Bangladeshi research firm "Mitra and Associates" under the authority of the National Institute for Population Research and Training. Financial and technical supports were provided by the U.S. Agency for International Development and the ICF International of Rockville, respectively.

\subsection{Sample design}

The survey is based on a two stage stratified sample of households. In the first stage, 600 enumeration areas were selected with probability proportional to the enumeration area size, with 207 clusters in urban areas and 393 in rural areas. In the second stage of sampling, a systematic sample of 30 households on average from complete list of household was selected per enumeration area to provide statistically reliable estimates of key demographic and health variables for the country. With this design, the survey selected 18,000 residential households, which were expected to result in completed interviews with about 18,000 ever married women. All ever married women aged 15-49 years who stayed at the selected households the night before the survey were eligible for the survey.

\subsection{Variables of interest}

The identification of determinants of birth interval is a big challenge in the real world. In rural area there was significant relation between socio demographic variables and birth interval. ${ }^{13,14}$ In Iran, there was significant association between birth interval with maternal age, duration of breast feeding, sex of child, history of still births, and regular attendance at family planning clinics. ${ }^{15}$ Fallahian et al. showed that the duration of breastfeeding and the method of contraceptive used were significantly associated factors with birth intervals. ${ }^{16}$ Mothers age at marriage is measured to be an important variable in the fertility process and it is negatively associated with birth interval. ${ }^{17,18}$ Education has always been an important variable in birth. ${ }^{19}$

In general, birth interval depends on two successive live births. The duration between first live birth and first cohabitation of married couple is considered first birth interval. Other intervals are calculated by the difference between two successive live births. This study considered the approximate determinants of first birth interval as region, place of residence, mothers education, partners education, mothers age, mothers working status, contraceptive use, sex of household head, religion, wealth index and mass media exposure. But for the other birth intervals the approximate determinants as sex of previous child, survival status of previous child, duration of previous birth interval and all the determinants of first birth interval. The necessary and required categories for demographic and socio-economic factors have been presented in Table 1.

The response variable for this study is birth interval. Successful birth is considered as success event and otherwise censored. The event time is defined as the interval between date of marriage and a live birth or censoring. Women who gave first birth but not second birth or those who were not even impregnated during the survey period are considered as censored for second birth interval analysis and this is the same for third birth interval. Pregnancy is the time during which one or more offspring develops inside a woman. Childbirth occurs just over nine lunar months, where each month is about $291 / 2$ days. Women having birth interval time bellow nine months, sterilized women and no dejure residence of women are excluded from this study.

\subsection{Cox proportional hazard model and its extension}

In general, survival analysis examines the relationship between survival status and covariates. Cox proportional hazard model is the most important model for survival analysis because it investigates the effects of the covariates on survival. ${ }^{20}$

Let $Y_{i}$ denotes the observed time (either censoring time or event time) for subject $i$. Let $C_{i}$ be the indicator that the time corresponds to an event (i.e. if $C_{i}=1$ the event occurred and if $C_{i}=0$ the time is a censoring time). Let $X_{i}=\left\{X_{i 1}, X_{i 2}, \ldots, X_{i p}\right\}$ be the realized values of the 
covariates for subject, $i$. The mathematical form of hazard function for the Cox proportional hazard model is:

$h\left(t / X_{i}\right)=h_{0}(t) \exp \left(\beta_{1} X_{i 1}+\beta_{2} X_{i 2}+\ldots+\beta_{p} X_{i p}\right)$

Or, $\quad h\left(t / X_{i}\right)=h_{0}(t) \exp \left(X_{i} \beta\right)$

This expression gives the hazard rate at time $t$ for the subject $i$ with covariate vector (explanatory variables) $X_{i}$.

The usual Cox proportional hazard model requires time-to-event data to be independent. ${ }^{21}$ Frailty is an unobserved random proportionality factor that changes the hazard function of an individual or a group of related individuals. In Cox proportional hazard model, it is assumed that the correlations are due to the unobservable group specific covariates and one approach to adjust all the unobservable covariates is to include a non-negative valued random term, known as frailty. Such extension of Cox proportional hazard model is known as frailty model. Frailty model is becoming more and more popular in the area of survival analysis and commonly used for analyzing correlated time-to-event data. ${ }^{22}$

One key problem in frailty model is choice of the frailty distribution. The most frequently used frailty distributions are gamma distribution, positive stable distribution, power variance function (PVF) distribution, inverse Gaussian distribution, compound Poisson distribution and lognormal distribution. ${ }^{23}$ Among them the most common and important frailty distribution is the gamma distribution. From a computational and analytical point of view the gamma distribution fits very well to failure data, because it is easy to derive the closed form expressions of survival, density and the hazard function. ${ }^{23}$

\subsection{Statistical analysis}

Since this study includes censored data, the survival analysis methods have been used to assess the significant impacts of different variables on the birth interval that leads to visualize the dominant factors affecting fertility in Bangladesh. Descriptive statistics served to illustrate the general characteristics of the variables. Kaplan-Meier estimator is used to find out the estimated mean with standard error and median value of different categories of the considered covariates and $\log$ rank test is used to test the significance of different categorical factors under this study. The Cox proportional hazard model is used to determine the effects of various factors on first birth interval. The extension of Cox proportional hazard model known as frailty model which is used to determine the effects of various factors on second and third birth intervals because of heterogeneity in birth intervals due to mother. The exponent of the coefficients of Cox proportional hazard model and frailty model is hazard ratio and have been used to calculate the factors change in the hazard rate associated with the changes of covariates. In this study $p$-value less than 0.05 is considered to be statistically significant. All statistical analyses are performed by SPSS version 15.0 and R.3.3.3.

\section{Results}

There were 13370, 11952 and 8871 women in this study among whom $92.40 \%, 76.80 \%$ and $61.60 \%$ had experienced of live birth and the rest $7.60 \%, 23.20 \%$ and $38.40 \%$ were censored for first, second and third birth, respectively. The average ( \pm SD) age of the ever married women for first, second and third births are 19.10 ( \pm 03.89), 23.13 ( \pm 05.12$)$ and $27.78( \pm 06.50)$ years, respectively. For the ever married women the estimated average ( \pm SE) duration of first, second and third births are $39.05( \pm 0.47), 76.38( \pm 1.13)$ and 135.27 ( \pm 1.93 ) months, respectively, but the estimated median duration of births for first, second and third births are 26, 46 and 58 months, respectively.

Table 2 provides descriptive statistics of the selected covariates for different birth intervals. The result shows that the percentage of families increased with an increasing number of birth in Rangpur, but decreased in Dhaka division. Among the ever married women, $64.61 \%$ gives at least one birth live in rural area. The percentages of rural people are increasing with respect to number of birth compared to urban people. The percentage of illiterate and primary educated mothers' birth significantly increased from $23.64 \%$ to $30.54 \%$ and $28.15 \%$ to $31.60 \%$ but secondary and higher educated mothers' birth significantly decreased from $37.94 \%$ to $31.45 \%$ and $10.28 \%$ to $6.41 \%$ for first birth to third birth respectively. The same scenario is discernible for partners education. In this study the majorities $(88.37 \%)$ of the household head are male, and $90.30 \%$ are Muslim. For some women whose families were not connected with any mass media and their numbers of birth increased from $39.45 \%$ to $51.62 \%$. The births increased from $35.75 \%$ to $38.77 \%$ in poor family but this scenario is different for rich family and the number of births decreased from $44.38 \%$ to $41.24 \%$. Around $74.24 \%$ women had first birth at the age of less than 21 years, $59.26 \%$ women had second birth and also $65.02 \%$ women had third birth at the age 21-30 years. Overall, both sexes of the child are equal for each birth and for all births the survival status of child is around $92 \%$. In case of duration of the birth interval, maximum $45.65 \%$ have less than 24 months for first birth, 39.57\% had $24-48$ months for second birth, and $47.58 \%$ had more than 48 months for third birth.

Table 2 also shows mean and median duration of birth according to the different covariates. With the rising of wealth index, mothers and their partners education level, the birth interval significantly increased for two or more births, but it had no effect on first birth.

Table 3 presents the different values of hazard ratio of Cox proportional hazard model and frailty model. Rural women are significantly more likely to have experienced first, second and third birth intervals in comparison to urban women.

Highly educated mothers are significantly more likely to have experienced live birth in case of first birth interval (HR: 1.86; C.I.: 1.70-2.03) and significantly less likely to have experienced live birth in case of third birth interval (HR: 0.47; C.I.: 0.39-0.58) if compared to others. More generally, mothers with primary, secondary and higher education are less likely to experience the live birth than uneducated mother for second and third birth interval. Partners education (primary and secondary level) is a protective factor for the next live birth for second and third birth interval. Higher education of partners is more likely to experience to the live birth in case of first, second and third birth intervals in comparison to uneducated partners.

Female household head is more likely to experience the next live birth in comparison to male household head for first and second birth interval but less likely to experience the next live birth and significantly protective factor for third birth intervals (HR: 0.86; C.I.: 0.78-0.95). Mothers working status for first, second and third birth interval is less likely to the experience in comparison to non-working women and it is also a significantly protective factor for third birth intervals (HR: 0.94; C.I.: 0.88-1.00). Mass media plays an important role in protecting different birth intervals. Non-Muslim family is also significantly more likely to experience the next live birth in comparison to Muslim family for first birth interval (HR: 1.12; C.I.: 1.06-1.19) but less likely to experience the next live birth for third birth interval (HR: 0.88; C.I.: 0.79-0.97). Contraceptive use is a significant protective factor for third birth interval (HR: 0.90; C.I.: 0.85-0.96) and contraceptive use for first and second birth intervals are significantly more practiced compared to the non-users of contraceptive. Wealth index (rich and middle class family) is approximately equally likely to the experience in comparison to poor family. In case of first birth interval, previous birth interval is not used. But women with more than 48 months birth interval are significantly more likely to experience the next live birth for second birth interval (HR: 1.92; C.I.: 1.79-2.06). 


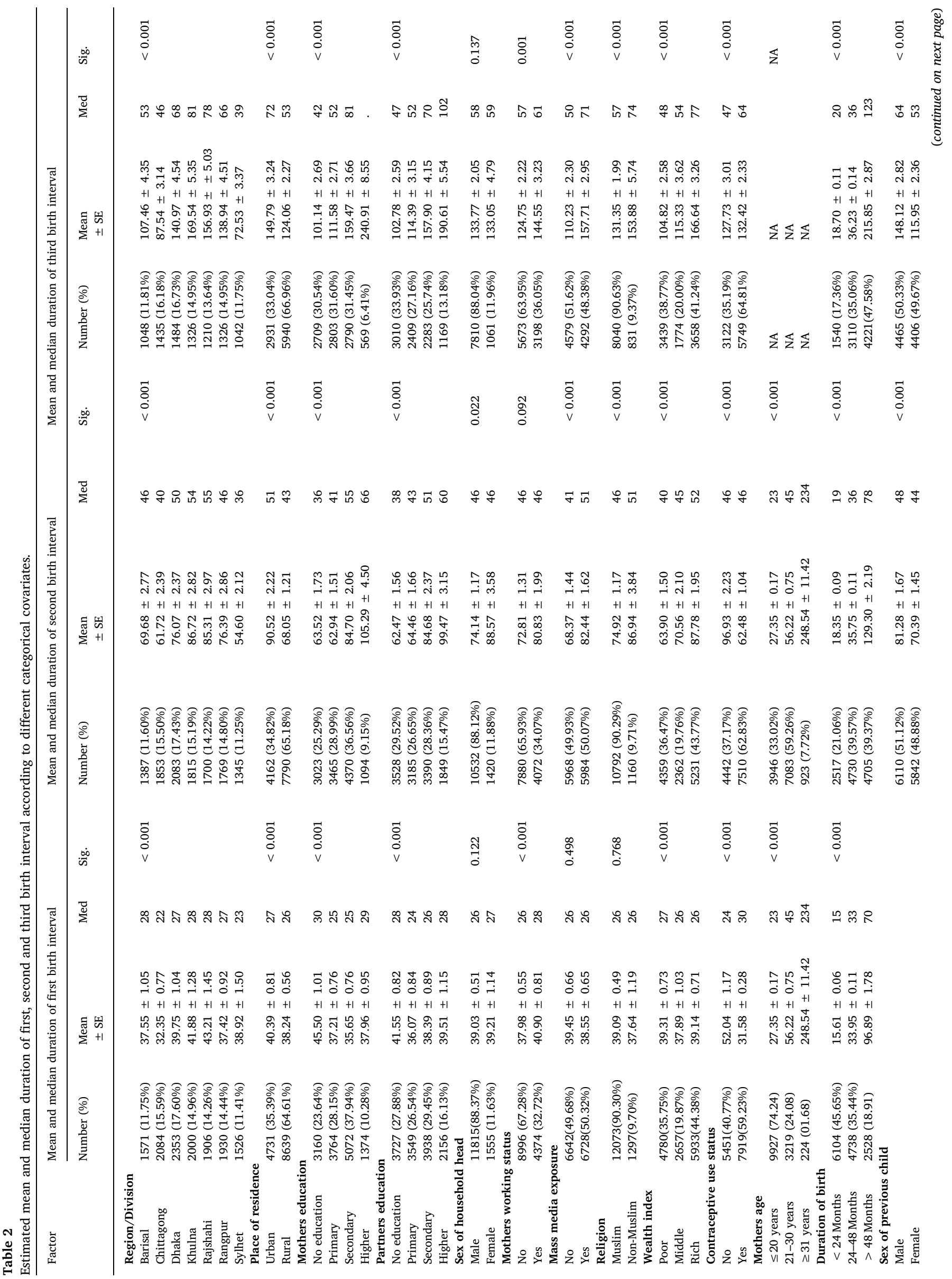




\section{Discussion}

As far as we know, there is not yet any study done on different birth intervals using BDHS 2014 data. To analyze the birth intervals, different statistical techniques and models are developed and carried out. Therefore, there is no scope for compares the developed statistical techniques and models in the present study with those reported in other studies. But it is important to compare this study with studies carried out in other countries.

Bangladesh is the world's eighth most populous country with 160 million people. ${ }^{24}$ The controlling of population growth encourages the people to longer births intervals. ${ }^{25}$ The estimated average duration of first two live births are 39 and 76 months, however, it is higher than the average child spacing period of Saudi Arabian children. ${ }^{14,26}$ This study also found that the estimated median intervals of first two live births are 26 and 46 months but the median birth interval of 55 developing countries was about 32 months. ${ }^{27}$ Higher education of mother is a significant protective factors for the third birth interval in comparison to first and second birth interval but Singh et al., Rajaram et al. and Gandotra at al. found that higher education of woman was a protective factor for first birth interval. ${ }^{28-30}$ Mass media is a protective impact on higher order birth interval. This finding is supported by Singh et al. and Gandotra et al. ${ }^{28,30}$

Findings of this study indicate that without any doubt the mothers working status is a more significant protective factor for the first and third birth intervals. This finding is supported by Singh et al. but not by Trussell et al. and Richter et al., who identified that employed women were significantly less likely to go for the next birth. ${ }^{28,31,32}$ The covariates contraceptive use is a significant protective factor for third birth interval but not protective factor for first and second birth interval. The result of third birth interval is supported by Singh et al. ${ }^{28}$ Mothers in rural area are not protective for all birth intervals and this result is supported by Singh et al., and Swenson \& Thang for first and second birth interval. ${ }^{28,33}$ Mothers age is a significant protective factor for all birth intervals and is supported by Swenson \& Thang. ${ }^{33}$ Rich families are also more protective for third birth interval and this is supported by Yohannes et al. ${ }^{1}$ However, previous female child is not a protective factor for the second and third birth intervals. The present study does not indicate the likelihood of it being a protective factor at any birth interval. Survival status of previous child emerged as a significant protective factor for the second and third birth intervals. This finding is in line with many other studies like Oheneba Sakyi \& Heaton, Ojha and Palloni \& Hantamala. ${ }^{34-36}$ If the number of birth increases, mothers education (primary, secondary and higher education), partners education (primary and secondary) and contraceptive use also decrease.

\section{Conclusion}

In this study, all analysis has been used to investigate the association and figure out the potential determinants of first, second and third birth interval in Bangladesh using BDHS-2014 data. This study shows that some important covariates, which have been used in the models and varied among the birth intervals. Using log rank test we have found that the covariates division, place of residence, mothers education, partners education, contraceptive use, mothers age, sex of the previous child, duration of previous birth are significantly associated with all considered number of births. The covariates place of residence, contraceptive use status and mothers age have significant impact on all birth intervals. Mothers education, sex of household head, mothers working status, and religion are significant factors for first and third birth intervals. Previous sex of the child, previous survival status of child and previous duration of birth are also significant factors for second and third birth intervals. However, partners education and wealth index have no significant impact on any birth intervals. This study emphasizes the importance of increasing the partners education, regional and religion studies, role of household head and mass media 
Table 3

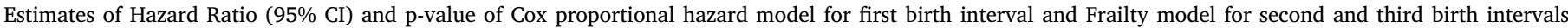
according to different categorical variables.

\begin{tabular}{|c|c|c|c|c|c|c|}
\hline & \multicolumn{2}{|l|}{ First birth interval } & \multicolumn{2}{|c|}{ Second birth interval } & \multicolumn{2}{|c|}{ Third birth interval } \\
\hline & HR (95\% CI) & p-value & HR $(95 \% \mathrm{CI})$ & p-value & HR $(95 \% \mathrm{CI})$ & p-value \\
\hline \multicolumn{7}{|c|}{ Region/Division } \\
\hline Barisal & 1.00 & & 1.00 & & 1.00 & \\
\hline Chittagong & $1.30(1.21,1.39)$ & $<0.001$ & $1.38(1.26,1.51)$ & $<0.001$ & $1.16(1.04,1.29)$ & 0.006 \\
\hline Dhaka & $1.07(1.00,1.15)$ & 0.055 & $0.93(0.85,1.02)$ & 0.100 & $0.85(0.76,0.95)$ & 0.003 \\
\hline Khulna & $0.96(0.89,1.03)$ & 0.238 & $0.77(0.70,0.85)$ & $<0.001$ & $0.74(0.66,0.83)$ & $<0.001$ \\
\hline Rajshahi & $0.97(0.90,1.04)$ & 0.342 & $0.77(0.70,0.84)$ & $<0.001$ & $0.72(0.64,0.81)$ & $<0.001$ \\
\hline Rangpur & $1.00(0.93,1.07)$ & 0.983 & $0.87(0.80,0.96)$ & 0.003 & $0.72(0.65,0.81)$ & $<0.001$ \\
\hline Sylhet & $1.47(1.36,1.59)$ & $<0.001$ & $1.62(1.47,1.79)$ & $<0.001$ & $1.41(1.26,1.58)$ & $<0.001$ \\
\hline \multicolumn{7}{|c|}{ Place of residence } \\
\hline Urban & 1.00 & & 1.00 & & 1.00 & \\
\hline Rural & $1.05(1.01,1.09)$ & 0.024 & $1.10(1.04,1.16)$ & 0.001 & $1.10(1.03,1.18)$ & 0.005 \\
\hline \multicolumn{7}{|c|}{ Mothers education } \\
\hline No education & 1.00 & & 1.00 & & 1.00 & \\
\hline Primary & $1.16(1.11,1.22)$ & $<0.001$ & $0.89(0.83,0.95)$ & $<0.001$ & $0.75(0.70,0.81)$ & $<0.001$ \\
\hline Secondary & $1.32(1.25,1.40)$ & $<0.001$ & $0.72(0.67,0.78)$ & $<0.001$ & $0.53(0.48,0.58)$ & $<0.001$ \\
\hline Higher & $1.86(1.70,2.03)$ & $<0.001$ & $0.89(0.79,1.01)$ & 0.070 & $0.47(0.39,0.58)$ & $<0.001$ \\
\hline \multicolumn{7}{|c|}{ Partners education } \\
\hline No education & 1.00 & & 1.00 & & 1.00 & \\
\hline Primary & $1.10(1.04,1.15)$ & $<0.001$ & $0.95(0.89,1.02)$ & 0.140 & $0.98(0.91,1.06)$ & 0640 \\
\hline Secondary & $1.05(0.99,1.11)$ & 0.112 & $0.92(0.86,0.99)$ & 0.024 & $0.99(0.90,1.08)$ & 0.780 \\
\hline Higher & $1.07(0.99,1.15)$ & 0.076 & $1.10(0.99,1.21)$ & 0.066 & $1.15(1.01,1.32)$ & 0.033 \\
\hline \multicolumn{7}{|c|}{ Sex of household head } \\
\hline Male & 1.00 & & 1.00 & & 1.00 & \\
\hline Female & $1.07(1.01,1.13)$ & 0.033 & $1.03(0.95,1.11)$ & 0.520 & $0.86(0.78,0.95)$ & 0.002 \\
\hline \multicolumn{7}{|c|}{ Mothers working status } \\
\hline No & 1.00 & & 1.00 & & 1.00 & \\
\hline Yes & $0.95(0.91,0.99)$ & 0.007 & $0.95(0.91,1.00)$ & 0.052 & $0.94(0.88,1.00)$ & 0.035 \\
\hline \multicolumn{7}{|c|}{ Mass media exposure } \\
\hline No & 1.00 & & 1.00 & & 1.00 & \\
\hline Yes & $0.99(0.94,1.04)$ & 0.622 & $0.98(0.91,1.04)$ & 0.400 & $0.97(0.89,1.04)$ & 0.380 \\
\hline \multicolumn{7}{|l|}{ Religion } \\
\hline Muslim & 1.00 & & 1.00 & & 1.00 & \\
\hline Non-Muslim & $1.12(1.06,1.19)$ & $<0.001$ & $1.05(0.97,1.14)$ & 0.260 & $0.88(0.79,0.97)$ & 0.014 \\
\hline \multicolumn{7}{|l|}{ Wealth index } \\
\hline Poor & 1.00 & & 1.00 & & 1.00 & \\
\hline Middle & $1.00(0.95,1.06)$ & 0.941 & $0.98(0.92,1.06)$ & 0.660 & $1.04(0.96,1.14)$ & 0.330 \\
\hline Rich & $1.00(0.94,1.06)$ & 0.921 & $1.01(0.93,1.09)$ & 0.890 & $1.02(0.92,1.12)$ & 0.720 \\
\hline \multicolumn{7}{|c|}{ Contraceptive use status } \\
\hline No & 1.00 & & 1.00 & & 1.00 & \\
\hline Yes & $1.36(1.31,1.41)$ & $<0.001$ & $1.27(1.21,1.34)$ & $<0.001$ & $0.90(0.85,0.96)$ & 0.002 \\
\hline \multicolumn{7}{|l|}{ Mothers age } \\
\hline$\leq 20$ years & 1.00 & & 1.00 & & 1.00 & \\
\hline $21-30$ years & $0.31(0.30,0.33)$ & $<0.001$ & $0.20(0.19,0.21)$ & $<0.001$ & $0.22(0.20,0.25)$ & $<0.001$ \\
\hline$\geq 31$ years & $0.04(0.03,0.05)$ & $<0.001$ & $0.02(0.01,0.03)$ & $<0.001$ & $0.02(0.01,0.03)$ & $<0.001$ \\
\hline \multicolumn{7}{|c|}{ Sex of previous child } \\
\hline Male & & & 1.00 & & 1.00 & \\
\hline Female & & & $1.15(1.10,1.20)$ & $<0.001$ & $1.24(1.17,1.32)$ & $<0.001$ \\
\hline \multicolumn{7}{|c|}{ Survival status of previous child } \\
\hline Died & & & 1.00 & & 1.00 & \\
\hline Alive & & & $0.41(0.38,0.45)$ & $<0.001$ & $0.50(0.45,0.55)$ & $<0.001$ \\
\hline \multicolumn{7}{|c|}{ Previous birth interval } \\
\hline$<24$ months & & & 1.00 & & 1.00 & \\
\hline 24-48 months & & & $1.23(1.17,1.30)$ & $<0.001$ & $1.06(0.99,1.14)$ & 0.120 \\
\hline$>48$ months & & & $1.92(1.79,2.06)$ & $<0.001$ & $0.99(0.91,1.08)$ & 0.840 \\
\hline
\end{tabular}

HR, Hazard Ratio; 95\% CI, 95\% confidence interval.

exposure, and awareness of contraceptive use.

\section{Ethics approval}

We have used secondary dataset taken from the Demographic and Health Surveys (DHS) Program website (https://dhsprogram.com/ data/). No ethics approval is required for this dataset.

\section{Conflicts of interest}

None declared.

\section{Claiming interest}

Authors are not interested to face any claim about their study.

\section{Author's contributions}

Benojir Ahammed have designed the study and involved in data analysis and interpreted the result of the study and finally drafted the main manuscript. Md. Rasel Kabir and Md. Menhazul Abedin have contributed in statistical analyses and provided overall help to prepare the manuscript. All authors have read and approved the final version of the manuscript. 


\section{Funding}

This research did not receive any specific grant from funding agencies in the public, commercial, or not-for-profit sectors.

\section{Acknowledgement}

Authors are profound acknowledge to Demographic and Health Surveys (DHS) Program to provide data and also authors are debated to the Statistics Discipline, Khulna University where this study is conducted. Authors are confessing uncountable debts to authors of different articles are used in this study. Thanks to Prof. Dr. Md. Rezaul Karim, Department of Statistics, Rajshahi University, Bangladesh, and Molla Azizur Rahman, English Discipline, Khulna University, Bangladesh, also thanks to the editor and reviewers for their comments and criticism to improve this paper.

\section{References}

1. Yohannes S, Wondafrash M, Abera M, Girma E. Duration and determinants of birth interval among women of child bearing age in Southern Ethiopia. BMC Pregnancy Childbirth. 2011;11:1-6.

2. Ayanaw A. Proximate Determinants of Birth Interval Length in Amhara Region: The Case of Fagita Lekoma District, Awizone. Ethiopia: Addis Ababa; 2008.

3. Yohannis F, Yemane B, Alemayehu W. Differentials of fertility in rural Butajira. Ethiop $J$ Health Dev. 2003;17:17-25.

4. Kamal A, Pervaiz MK. Determinants of higher order birth intervals in Pakistan. $J$. Stat. 2012;19:54-82 2012.

5. Srinivasan K. Birth Interval Analysis in Fertility Surveys. Netherlands: Voorburg: International Statistical Institute; 1980:49.

6. Ethiopia Central Statistical Agency and ORC Macro. Ethiopia demographic and heath survey. https://dhsprogram.com/pubs/pdf/FR179/FR179[23June2011].pdf; 2005 2006 .

7. Fotso JC, Cleland J, Mberu B, Mutua M, Elungata P. Birth spacing and child mortality: an analysis of prospective data from the Nairobi urban health and demographic surveillance system. J Biosoc Sci. 2013;45:779-798.

8. Zhu BP, Rolfs RT, Nangle BE, Horan JM. Effect of the interval between pregnancies on perinatal outcomes. N Engl J Med. 1999;340:589-594.

9. Fallahzadeh H, Farajpour Z, Emam Z. Duration and determinants of birth interval in Yazd, Iran: a population study. Iran J Reproductive Med. 2013;11:379-384.

10. Clayton DG. Some odds ratio statistics for the analysis of ordered categorical data. Biometrika. 1974:61:525-531.

11. Martin EC. A study of the effect of birth interval on the development of 9-year-old schoolchildren in Singapore. J Trop Pediatr Environ Child Health. 1979;25:46-76.

12. Bangladesh Demographic and Health Survey 2014. National Institute of Population Research and Training (NIPORT), Mitra and Associates, and ICF International; 2016https://dhsprogram.com/pubs/pdf/FR311/FR311.pdf.
13. Al-Nahedh NN. The effect of socio demographic variables on child spacing in rural Saudi Arabia. East Mediterr Health J. 1999:5:136-141.

14. Bella H, Al-Almaie SM. Do children born before and after adequate birth intervals do better at school? J Trop Pediatr. 2005;51:265-270.

15. Hajian-Tilaki KO, Asnafi N, Aliakbarnia-Omrani F. The Patterns and determinants of birth intervals in multiparous women in Babol, Northern Iran. Southeast Asian J Trop Med Publ Health. 2009;40:852-860.

16. Fallahian M, Kazemnegat A, Ebrahimi N. Determinant of short birth interval. $J$ Behboud Kermanshah Med Sci Univ Iran. 1993;18:35-48.

17. Clegg E. Starting, spacing and stopping in the reproductive histories of outer Hebridean families. J Biosoc Sci. 2001;33:405-426.

18. Nahar L, Rahman M. Changes in socio-economic differentials of age at marriage and first birth during 1983-1994 in Matlab Bangladesh. Demogr India. 2006;35:1-14.

19. Shayan Z, Ayatollahi SMT, Zare N, Moradi F. Prognostic factors of first birth interval using the parametric survival models. Iran J Reproductive Med. 2014;12:125-130.

20. Cox DR. Regression models and life tables. J Roy Stat Soc B. 1972;34:187-220.

21. Singh R, Mukhopadhyay K. Survival analysis in clinical trials: basics and must know areas. Perspect Clin Res. 2011;2:145-148

22. Mahmood S, Zainab B, Latif AHMM. Frailty modeling for clustered survival data: an application to birth interval in Bangladesh. J Appl Stat. 2013;40:2670-2680.

23. Hanagal DD, Sharma R. Comparison of frailty models for acute leukemia data under gompertz baseline distribution. Commun Stat Theor Methods. 2015;44:1338-1350.

24. Bhattacharjee R, Hasan MA. The activities of Bangladesh water development board on the social environment of Bhadrabila union, Narail sadar upazila, Bangladesh. Asian J. Med. Biol. Res. 2016;2:297-303.

25. Abdel-Fattah M, Hifnawy T, Said TIEI, Moharam MM, Mahmoud MA. Determinants of birth spacing among Saudi women. J Family Community Med. 2007;14:103-111.

26. Madani KA, Khashoggi RH, Al-Nowaisser AA, Nasrat HA, Khalil MH. Lactation amenorrhea in Saudi women. J Epidemiol Community Health. 1994;48:286-289.

27. Rasheed P, Al-Dabal BK. Birth interval: perceptions and practices among urban based Saudi Arabian women. East Mediterr Health J. 2007;13:881-892.

28. Singh R, Tripathi V, Kalaivani M, Singh K, Dwivedi SN. Determinants of birth intervals in Tamil Nadu in India: developing Cox hazard models with validations and predictions. Rev Colomb Estadística. 2012;35:289-307.

29. Rajaram S, Rao S, Pandey A. Birth interval dynamics in Goa: a parity specific analysis. Demography. 1994;23:67-81.

30. Gandotra M, Retherford R, Pandey A, Luther N, Mishra V. Fertility in India. National Family Health Survey Subject Reports 9, Mumbai Honolulu: International Institute for Population Sciences; 19981998.

31. Trussell J, Martin L, Fledman R, Palmore J, Concepcion M, Bakar DA. Determinant of birth interval length in the Phillipines, Malaysia and Indonesia: a hazard model analysis. Demography. 1985;22:145-168.

32. Richter K, Podhisita C, Chamratrithirong A, Soonthorndhada K. The impact of child care on fertility in urban Thailand. Demography, 1994:31:651-662 1994.

33. Swenson I, Thang NM. Determinants of birth intervals in Vietnam: a hazard model analysis. J Trop Pediatr. 1993;39:163-167.

34. Ojha A. The effect of sex preference on fertility in selected states of India. J Fam Welfare. 1998;44:42-48.

35. Oheneba-Sakyi Y, Heaton TB. Effects of socio-demographic variables on birth intervals in Ghana. J Comp Fam Stud. 1993;24:113-135

36. Palloni A, Hantamala R. The effects of infant mortality on fertility revisited: new evidence from Latin America. Demography. 1999;36:41-75. 